\title{
Kadın sünnetinin alt üriner sistem semptomlarına etkisi ve hemșirelik bakımı
}

\section{The effect of female circumcision on lower urinary tract symptoms and nursing care}

\author{
Ömercan Aksoy'®, Ergül Aslan²®
}

\section{öz}

Kadın sünneti (genital mutilasyonu), tıbbi olmayan nedenlerle kadının dış genital organlarının kısmen ya da tamamen çıkarılmasını veya genital organlara zarar verilmesini içeren işlemlerdir. Kadın sünnetinin akut ve kronik olmak üzere birçok riski bulunmaktadır. Dünya üzerindeki çoğu ülke bu uygulamayı yasaklamıştır. Doğrudan alt üriner sisteme zarar veren bir uygulama olmasından dolayı bu sistemde rahatsızlıklar görülmektedir. Akut idrar retansiyonu, üriner sistem enfeksiyonları ve ağrılı veya zor idrar yapma problemleri en sık görülen sorunlardır. Üriner inkontinans problemleri kadın sünneti olan bireylerde daha fazla oranda görülmektedir. Konunun mahrem olması, coğrafi olarak ulaşımın zor olması ve sağlık merkezlerine uzaklık nedeniyle özellikle akut dönemde oluşan ürojinekolojik problemler fark edilmemektedir. Hemşireler, özellikle risk altındaki kızların belirlenmesinde ve tanılanmasında toplum katmanlarında bireye en yakın sağlık profesyoneli olması nedeniyle büyük rol oynamaktadır.

Anahtar Kelimeler: alt üriner sistem semptomları, infibülasyon, kadın sünneti, klitoridektomi

\section{Gíriș}

Kadın sünneti (genital mutilasyonu), tıbbi olmayan nedenlerle kadının dış genital organlarının kısmen ya da tamamen çıkarılmasını veya genital organlara zarar verilmesini içeren işlemlerdir. ${ }^{[1]}$ Birçok ülke kadın sünnetini insan hakları ihlali ve yasal açıdan yasak olarak tanımlamasına rağmen, halen 30'dan fazla Afrika ülkesinde ve birkaç Asya ve Orta Doğu ülkesinde rapor edilmektedir. ${ }^{[2]}$ Uluslararası göçün sonucu olarak Avrupa ve Kuzey Amerika'da çeşitli

'İstanbul Üniversitesi - Cerrahpaşa, Lisansüstü Eğitim Enstitüsü, Kadın Sağlığı ve Hastalıkları Hemşireliği Anabilim Dalı, İstanbul, Türkiye

${ }_{2}^{2}$ Istanbul Üniversitesi - Cerrahpaşa, Florence Nightingale Hemşirelik Fakültesi, Kadın Sağlığı ve Hastalıkları Hemşireliği Anabilim Dalı, İstanbul, Türkiye

Yazışma Adresi/ Correspondence:

Hemşire Ömercan Aksoy

Izzetpaşa Mahallesi, Abide-i Hürriyet Cd, 34381 Şişli 34381 İstanbul, Türkiye

Tel. $\quad+905456471404$

E-mail: omercan.aksoy@ogr.iu.edu.tr

Gelis/ Received: $\quad 24.01 .2020$

Kabul/ Accepted: 10.05 .2020

\section{ABSTRACT}

Female circumcision (genital mutilation) is the procedure involving partial or complete removal of the woman's external genital organs or damage to the genital organs for non-medical reasons. Female circumcision has many risks, including acute and chronic. Most countries in the world have banned this practice. As it is an application that directly damages the lower urinary system, discomfort is observed in this system. Acute urinary retention, urinary tract infections and painful or difficult urination problems are the most common problems. Urinary incontinence problems are more common in individuals with female circumcision. Urogynecological problems, especially in the acute period, are not noticed due to the fact that the subject is confidential, geographically difficult to reach and the distance to health centers. Nurses play a major role in identifying and diagnosing girls at risk, especially because nurses are the closest healthcare professionals to community.

Keywords: lower urinary tract symptoms, infibulation, female circumcision, clitoridectomy

azınlık gruplarında da bu işlemi geçirmiş veya geçirme ihtimali olan kadın bulunmaktadır. ${ }^{[3]}$ Dünya genelinde 200 milyondan fazla kişinin kadın sünnetine maruz kaldığı tahmin edilmektedir. Uygulama ortadan kaldırılmasına yönelik çabalara rağmen her yıl yaklaşık 3 milyon kız çocuğu kadın sünneti olma riski altındadır. Dünya Sağlık Örgütü (DSÖ) temel sağlık hizmetlerinin bir parçası olarak 2008 yılında kadın sünnetinin ortadan kaldırılması konusunda beyanat yayınlamıştır. ${ }^{[4]}$ Kadın sünnetinin çeşitli tipleri, akut ve uzun dönem sağlık sorunları bulunmaktadır. Hemşireler başta olmak üzere sağlık profesyonelleri kadın sünnetinin önlenmesi ve bu uygulamaya maruz kalan kişileri ortaya çıkararak bakımının sürdürülmesinde etkin rol almalıdır. Bu derlemenin amacı kadın sünnetinin alt üriner sistem semptomlarına etkisini incelemektir.

\section{KADIN SÜNNETININ TIPLERI}

Kadın sünnetinin dört tipi ve açıllamaları, Tablo 1'de tanımlanmıştır. ${ }^{[5]}$ 
Tablo 1. Kadın Sünnetinin Tipleri

\begin{tabular}{|c|c|}
\hline Tip I & $\begin{array}{l}\text { Klitorisin (klitoridektomi) ve/veya klitoral } \\
\text { örtünün tamamının veya bir kısmının çıkarıl- } \\
\text { ması }^{[5]}\end{array}$ \\
\hline Tip la & Klitoral örtünün çıkarılması (sünnet) (Şekil 1) \\
\hline Tip Ib & $\begin{array}{l}\text { Klitoral örtü ile klitorisin çıkarılması (klitoridek- } \\
\text { tomi) (Şekil 1) }\end{array}$ \\
\hline Tip II & $\begin{array}{l}\text { Klitorisin ve labia minörün kısmen veya tama- } \\
\text { men çıkarılması, labia majörün eksizyonu eşlik } \\
\text { edebilir veya etmeyebilir }{ }^{[5]}\end{array}$ \\
\hline Tip Ila & Sadece labia minörün çıkarılması (Şekil 2) \\
\hline Tip IIb & $\begin{array}{l}\text { Labia minör ve klitorisin kısmen veya tamamen } \\
\text { çıkarılması (Şekil 2) }\end{array}$ \\
\hline Tip Ilc & $\begin{array}{l}\text { Labia majör, labia minör ve klitorisin kısmen } \\
\text { veya tamamen çıkarılması (Şekil 2) }\end{array}$ \\
\hline $\begin{array}{l}\text { Tip III (İn- } \\
\text { fibülasyon) }\end{array}$ & $\begin{array}{l}\text { Klitorisin çıkartılarak ya da çıkartılmadan, labia } \\
\text { minör ve labia majörün kapatılarak vajinal } \\
\text { açıklı̆ın daraltılmasıdır. Bu uygulamada idrar } \\
\text { ve menstrual kan akımını sağlayacak küçük bir } \\
\text { delik oluşturulur }{ }^{[5]}\end{array}$ \\
\hline Tip Illa & $\begin{array}{l}\text { Klitorisin çıkartılarak ya da çıkartılmadan, labia } \\
\text { minörün çıkarılması ve sütur atılarak bir araya } \\
\text { getirilmesi (Şekil 3) }\end{array}$ \\
\hline Tip IIIb & $\begin{array}{l}\text { Klitorisin çıkartılarak ya da çıkartılmadan, labia } \\
\text { majörün çıkarılması ve sütur atılarak bir araya } \\
\text { getirilmesi (Şekil 3) }\end{array}$ \\
\hline Reinfibülasyon & $\begin{array}{l}\text { İnfibulasyonun bozulduğu durumlarda (örneğin } \\
\text { vajinal doğum) tekrar yapııması, yeniden sütur } \\
\text { atma işlemi }\end{array}$ \\
\hline Tip IV & $\begin{array}{l}\text { Kadın cinsel organlarına tibbi olmayan amaçlar } \\
\text { için uygulanan diğer tüm zararlı prosedürler, } \\
\text { örneğin: iğneleme, piercing, delme, soyma, } \\
\text { kazıma ve koterizasyon }{ }^{[5]}\end{array}$ \\
\hline
\end{tabular}
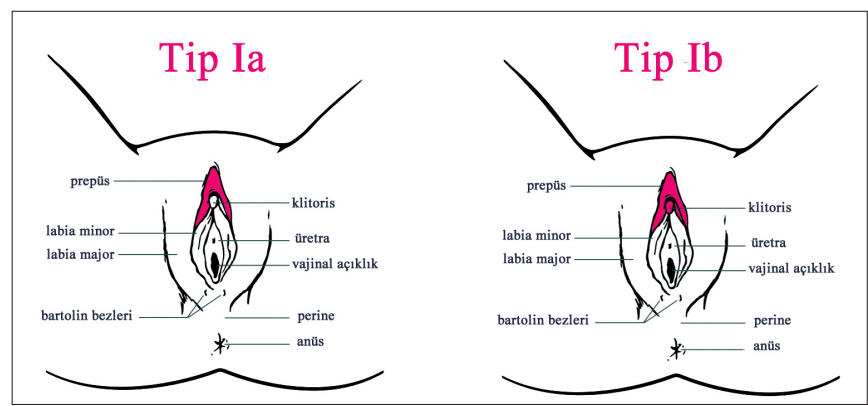

Şekil 1. Kadın Sünneti Tip la ve Ib. Bu işlem esnasında çıkartılan (pembe) veya etkilenen dokular (sarı) farklı renkte gösterilmiştir (WHO guidelines on the management of health complications from female genital mutilation. 2016:47).

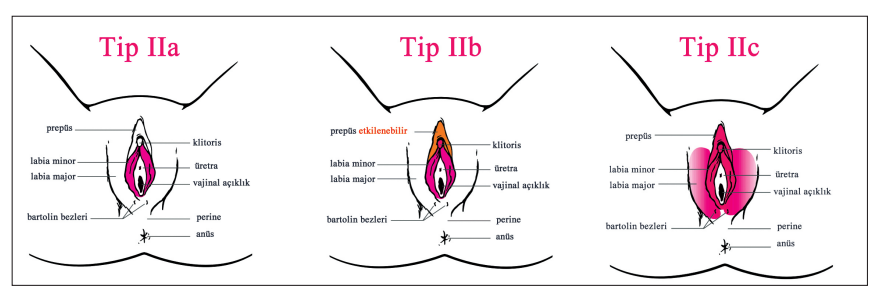

Şekil 2. Kadın Sünneti Tip Ila, Ilb ve Ilc. Bu işlem esnasında çıkartılan (pembe) veya etkilenen dokular (sarı) farklı renkte gösterilmiştir (WHO guidelines on the management of health complications from female genital mutilation. 2016:47).

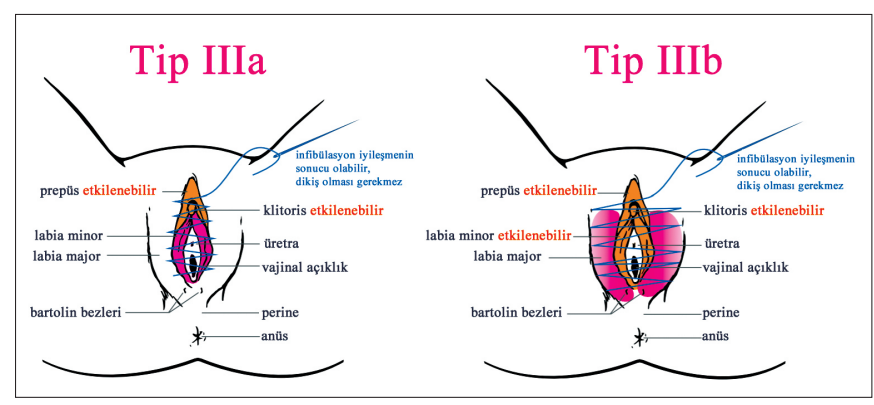

Şekil 3. Kadın Sünneti Tip IIla ve IIlb. Bu işlem esnasında çıkartılan (pembe) veya etkilenen dokular (sarı) farklı renkte gösterilmiştir (WHO guidelines on the management of health complications from female genital mutilation. 2016:47).

\section{KADIN SÜNNETININ SAĞLIK RISKLERi}

Kadın sünneti yapılan kadınların yaşamları boyunca komplikasyonlara maruz kalma riskleri büyüktür. İşlem acı verici ve travmatiktir. Genellikle kadın anatomisi veya olası komplikasyonların nasıl yönetileceği konusunda yetersiz bilgiye sahip uygulayıcılar tarafindan ve steril olmayan koşullarda gerçekleştirilir. Kadın sünnetinin doğrudan sağlık etkileriyle ilgili kesin veriler sağlamak mevcut çalışmaların küçük örneklem ile yapılması ve metodolojik kısıtlamaları nedeniyle zordur. ${ }^{[2,4]}$

Akut Riskler: Hemoraji, hematom, ağrı, şok, genital dokuda ödem, enfeksiyon, miksiyon problemleri, yara iyileşme problemleri ve ölüm. ${ }^{[2]}$

Obstetrik Riskler: Sezaryen, postpartum hemoraji, uzamış doğum eylemi, epizyotomi, deşüri ve laserasyonlar, müdahaleli doğum, zor doğum/distosi, hastanede fazla kalma süresi, ölü doğum ve erken yenidoğan ölümü, yenidoğan resüsitasyonu. ${ }^{[2]}$

Cinsel İşlev Riskleri: Disparoni, cinsel memnuniyet, cinsel istek ve uyarılma, lubrikasyon ve orgazmda azalma veya anorgazmi. ${ }^{[2]}$

Psikolojik Riskler: Travma sonrası stres bozukluğu (TSSB), anksiyete bozuklukları ve depresyon. ${ }^{[2]}$

Uzun Dönem Riskleri: Genital doku hasarı, vajinal akıntı, vajinal kaşıntı, menstrual problemler, üreme sistemi enfeksiyonları, kronik genital enfeksiyonlar, üriner sistem enfeksiyonları ve dizüri. ${ }^{[2]}$

\section{KADIN SÜNNETI VE ALT ÜRINER SISTEM SORUNLARI}

Kadın sünnetinin akut döneminde miksiyon problemleri görülse de üriner sistemi etkileyen sorunlar uzun dönem riskler arasında yer almaktadır. Kadın sünneti olan bireylere ulaşmanın ve takibini sağlamanın güç olması nedeniyle üriner sistem sorunları üzerinde çok fazla çalışılmamıştır. 
Zambon ve ark.'nın (2018) yaptıkları sistematik derleme sonucunda, kadın sünneti olan bireylerde üriner sistem sorunlarının genel prevalansı \%20 - \%30 arasında değiştiğini bulmuşlardır. Bu sorunlar arasında; tekrarlayan üriner sistem enfeksiyonları, alt üriner sistem semptomları, üriner retansiyon, ürogenital fistül, meatüs darlığı, üretral taş ve megaüretra en sık görülen semptomlardır. ${ }^{[6]}$

Kadın sünneti geçiren özellikle Tip III olanlar arasında tekrarlayan üriner sistem enfeksiyonları (ÜSE) de dahil olmak üzere idrar yolu enfeksiyonları gelişme riski daha yüksektir. Kadın sünneti olanlarda ÜSE genellikle idrarın obstrüksiyonu ve üriner staz nedeniyle ortaya çıkar. Bu durum, daha çok infinbule kadınlarda veya üretral açıklığın yaralandığı durumlarda ortaya çıkabilir. Bu tıkanıklık, normal idrar akışını etkiler ve bu durum sonucunda kadın idrar yaparken damlalar halinde gelmesine neden olur. Bunun sonucunda, idrar durgunlaşarak ÜSE'ya neden olabilecek bakterilerin çoğalmasına ortam hazırlar ve bu durum tekrar edebilir. ${ }^{[7]}$ Millet ve ark.'nın (2019) kadın sünneti olan bireylerde AÜSS belirlemek üzere yaptıkları sistematik derlemeye göre, akut üriner retansiyon oranını \%3-12 arasında bulmuştur. Uzun dönem komplikasyonlar açısından kadın sünneti olanlarda AÜSS prevalansı anlamlı şekilde yüksektir. Örn. kadın sünneti olan grupta miks üriner inkontinans 5,17 kat artmıştır. Kadın sünnetinin doku hasarı arttıkça AÜSS görülme sıklığı da o derece artmaktadir. ${ }^{[8]}$

Geynisman-Tan ve ark.'nın Amerika Birleşik Devletleri'nde kadın sünneti olan bireylerin AÜSS incelemek için kadın sünneti geçirmiş 30 kadını dahil ettikleri çalışmada, kadınların \%73'ü AÜSS varlığını bildirmiştir. \%53’ü sıkışma tip üriner inkontinans ve \%43'ü stres üriner inkontinansı bildirmiştir. \%47'si kesik kesik idrar yapma, \%40'ı idrar yapmada zorlanma ve \%30'u duraksama problemi bildirmiştir. ${ }^{[9]}$

Berg ve ark.'nın (2014) kadın sünneti olan bireylerin fiziksel sağlık sorunlarını incelemek için yaptıkları sistematik derleme ve meta-analizde, ürogenital sorunlar başlığı altında, idrar yaparken ağrı ve yanma şikayetlerinin kadın sünneti olmayanlara göre iki çalışmada 2,56 kat ve 1,66 kat daha fazla risk altında olduğunu göstermiştir. Kadın sünneti olan bireylerde uzun dönemde ÜSE'nin daha fazla görüldüğü saptanmıştır. ${ }^{[10]}$

Amin, Rasheed ve Salem'in 2013'de AÜSS'nı belirlemek için Mısır'da 251 kadın sünneti olan ve 181 olmayan bireyi çalışmaya dahil etmiştir. Kadın sünneti olanlarda en az bir tane AÜSS bildirmiştir. Mesane dolum semptomları açısından kadın sünneti olanlarda daha fazla semptom gösterilmiştir. Kadın sünneti olanlarda \%38,6 noktüri, \%23,5 kesik kesik idrar yapma, \%22,7 mesanenin tam boşaltılamadığı hissi olduğu bulunmuştur. Kadın sünneti olan bireylerde miks üriner inkontinans, sıkışma tip üriner inkontinans ve stres üriner inkontinans sırasıyla \%19,1, \%11,5 ve $\% 10,7$ olarak bulunmuştur. Aynı çalışmada idrar yaptıktan sonra damlama şikâyeti \% 19,1, idrar yaparken zorlanma \%13,9 ve yavaş akım \%12,3 olarak bulunmuştur. En az üç AÜSS bildiren kadınların oranı \%16,3 olarak bulunmuştur. Tip II ve III'de tüm AÜSS açısından Tip I'e göre daha fazla semptom bulunmuştur. Bunun nedeni olarak özellikle Tip III'de üretral meatüsü kapatacak girişim yapılması üriner sorunlara yol açabilmektedir. ${ }^{[11]}$ Obermeyer' in yaptığı sistematik derlemede kadın sünneti sonucu dizüri (\%58-64), üriner retansiyon (\%12-70), tekrarlayan ÜSE (\%2-38) ve inkontinans (\%6) raporlanmıştır. ${ }^{[12]}$ Iavazzo, Sardi ve Gkegkes tarafından kadın sünneti ve enfeksiyon durumunu belirlemek amacı ile yapılan 22.052 kadın sünneti vakasını içeren sistematik derlemede, üriner sistem enfeksiyonlarının kadın sünneti olanlarda özellikle de Tip III'de daha yüksek oranda bulunduğu vurgulanmıştır. ${ }^{[13]}$ Benzer şekilde Kaplan ve ark.'nın Gambia'da kadın sünneti komplikasyonlarını belirlemek için 871 kadınla yaptığı çalışmada 291'inin kadın sünnetine bağlı komplikasyon geçirdiği belirlenmiştir. Ürogenital enfeksiyon \%36,8 ile en yaygın komplikasyon olduğu ve Tip III kadın sünneti olanlarda diğer tiplere oranla daha fazla enfeksiyon görüldüğü belirlenmiştir. ${ }^{[14]}$

Elnashar ve Abdelhady'in Mısır'da yeni evli kadınlar üzerinde yaptıkları çalışmada, üriner problemler açısından, idrar yaparken yanma ve üriner inkontinans açısından kadın sünneti olan kadınlar ile olmayanlar arasında istatistiksel olarak anlamlı bir fark bulunmamıştır. ${ }^{[15]}$

Aldulcadir ve Dällenbach'ın vaka çalışmasında Tip III a/b kadın sünneti olan ve aşırı aktif mesane tanısı konulan bir olgu incelenmiştir. Başvuru şikayetleri, yavaş idrar yapma, idrar yaparken ıkınma, sıkışma ve sıkışma tip inkontinans olarak belirlenmiştir. İncelenen vaka, Tip III a/b olduğu için defibülasyon (infibüle labiaların cerrahi olarak açılmas1) operasyonu geçirmiş ve biofeedback tedavisi uygulanmıştır. Tedavi sonrası yaşam kalitesinde anlamlı derecede artış saptanmış ve idrar yapma güçlüğü önemli ölçüde ortadan kaldırılmıştır. ${ }^{[16]}$

Kadın sünneti konusunda yapılan çalışmaların kanıt düzeyi düşük olup, çok az sayıda randomize kontrollü çalışma bulunmaktadır. ${ }^{[8,11,15]}$ Alt üriner semptomlarını da ele alan vaka çalışmaları daha fazla yapılmıştır. ${ }^{[16-23]}$ Konunun hassas olması, ulaşımı güç bölgelerde uygulamanın yapılması, iletişim sorunları, mahremiyet kaygıları ve toplumsal baskı geniş örneklemde ve kanıt temelli araştırma yapmayı 
güçleştirmektedir. Coğrafi konum açısından Akdeniz bölgesi özellikle Afrika’dan gelen göçlere çok açı olan bir bölgedir. Türkiye de Avrupa’ya göçlerde bir köprü olarak görülmekte ve giderek göç yoğunluğu artmaktadır. Büyüyen göç tehlikesi açısından kadın sünneti konusunda sağlık profesyonellerinin bilgilenmesi oldukça önemlidir.

\section{KADIN SÜNNETI, ALT ÜRINER SISTEM SEMPTOMLARI VE HEMȘIRELIK YAKLAȘIMI}

Kadın sünneti geçirenlerle iletişimde hemşireler kullandıkları dile özen göstermeli, yargılayıcı ifadelerden uzak durmalı ve kadını küçük düşürücü "kesme" gibi kelimeler kullanılmamalıdır. Kadınlar, yargılayıcı tutumdan korktuğu için sağlık sorunları hakkında konuşmaktan kaçınabilmektedir. ${ }^{[24]}$

Kadın sünneti olanlar, vajinal ve rektal muayene konusunda da çekince yaşayabilir, cinsel yolla bulaşan enfeksiyon açısından taramaları reddedebilir. Özellikle üriner kateterizasyon ve servikal smear testi gibi girişimsel uygulamalar sağlık profesyoneli açısından çok zor olabilir. Hemşireler genital bölgeyi gördüğünde şok, tiksinme ve korku gibi tepkiler göstermemelidir. ${ }^{[2]}$

Hemşireler özellikle risk altındaki genç kızları tespit etme açısından önemli bir görev üstlenmektedirler. ${ }^{[25]}$ Hemşirelerin hangi alanda çalıştıklarına bakılmaksızın kadın sünneti olan bireylerle ilk karşılaşan ve ortaya çıkaran sağlık profesyoneli olduğu bildirilmiştir. Hemşirelerin kadın sünneti olan bireyler ile çalışırken en iyi uygulamaların farkında olmaları, özellikle kadın sünnetinin ne olduğu, nerede gerçekleştirildiği, nasıl önleneceği ve maruz kalan kadınların fiziksel ve duygusal olarak nasıl desteklenebileceğini bilmeleri gerekmektedir. ${ }^{[26]}$ Hemşireler kadın sünnetini gündeme getirme ve önleme potansiyeli olan öncü hizmetlerde rol alabilmesi için konunun hemşirelik temel eğitim ve mezuniyet sonrası programlarına dahil edilmesi gerekmektedir. ${ }^{[27]}$ DSÖ kadın sünneti yapılan kadınların bakımı için yayınladığı klinik el kitabında, ürolojik ve ürojinekolojik semptomlar için yapılması gerekenleri bildirmiştir ${ }^{[7]}$;

\section{Anamnez}

Kadın sünneti olanlar ürolojik veya ürojinekolojik semptomlar için ileri duruma veya saklanamayacak duruma gelinceye kadar bakım yardımı aramamaktadır. Bakım almak istediklerinde ise doğrudan genitoüriner sistemle ilgili olmayan semptomlardan bahsedebilirler. ${ }^{[7]}$ Hemşirelik yaklaşımında izlenecek adımlar;
- Kadınla tanışın ve kendinizi tanıtın.

- Şu anki şikâyetini sorun. Şikâyeti hakkında mümkün olduğunca fazla bilgi edinin.

- Eğer şikâyetinin kadın sünnetinden kaynaklı olduğunu düşünüyorsanız, uygulanan kadın sünneti de dâhil tüm işlemleri nazikçe sorun. Kendisinin de anlayabileceği bir terminoloji kullanın.

- Kadına sağlığı ve kadın sünnetinden kaynaklanabilecek sorunları hakkında bilgi paylaşmak isteyip istemediğini sorun.

- Doğrudan kadın sünneti ile ilişkili ürolojik veya ürojinekolojik komplikasyonları araştırın.

- Kadın sünnetinin onunla ilgilenmenize engel bir durum olmadığının ve aynı zamanda sağlık hizmetlerine erişimine engellemeyeceğinin güvenini verin.

- Kadının duygularını ifade etmesine ve paylaşmak istediği bilgiyi vermesine izin verin. Ağlamaya başlarsa, sabırlı olun ve destek verin.

- Dikkatlice dinleyin ve onunla empati kurun. Hastaya ilgi gösterin ve ona yardım edebileceğinizi belirtin. Kadın sünnetinin herhangi bir tipini geçirdiğinden emin olduktan sonra klinik muayene titizlikle ve profesyonel şekilde ele alınmalıdır.

- Kadın sünnetinin tipi ve komplikasyonları sağlık kurumunun politikası gereği kaydedilmelidir. ${ }^{[7]}$

\section{Klinik Muayene}

- Gizlilik ve mahremiyeti sağlayın.

- Kadına onu muayene edeceğinizi ve bunun genital muayeneyi içereceğini açıklayın.

- Bacaklarını ayırıp dizlerini bükerek sırt üstü yatmasını isteyin.

- Muayene ve inspeksiyon için yeterli alan açın. Klinik muayene hazırlığı aşamasında hastayı örtün.

- Ellerinizi iyice yıkayın ve eldiven giyin.

- Dış genitalleri açın ve inspeksiyon yapın.

- Her durum için aşağıda açıklanan yönetim prosedürlerini takip edin.

- Eldivenlerinizi çıkarın ve ellerinizi yıkayın.

- İşlemi tamamladıktan sonra iş birliğinden dolayı kadına teşekkür edin.

- Hastaya oturma pozisyonuna geçmesinde, giyinmesinde yardım edin ve işlemin bir sonraki adımı için rahatça oturmasını sağlayın.

- Bulgularınızı hasta ile paylaşın.

- Bulgularınızı kaydedin. ${ }^{[7]}$ 


\section{Akut İdrar Retansiyonunun Yönetimi}

İdrar retansiyonu, yaralanma sonucu idrar akışı esnasında oluşan korku, ağrı veya infibülasyona bağlı oklüzyon nedeniyle oluşabilmektedir. Akut idrar retansiyonu ise genital bölgede enflamasyon nedeniyle oluşur. ${ }^{[7]}$ Hemşirelik yaklaşımında izlenecek adımlar;

- İdrar retansiyonunun nedenini belirlemek için değerlendirme yapın.

- Akan su sesi dinletmek gibi idrar yapmaya teşvik edici hemşirelik becerilerini ve tekniklerini kullanın.

- Eğer ağrı ve korku nedeniyle idrar yapma güçlüğü devam ediyorsa hekim istemine göre analjezik verin ve kişisel destek sağlayın.

- Eğer halen idrar yapma güçlüğü devam ediyorsa foley kateter takın. Kateteri iki veya üç gün boyunca çekmeyin.

- Eğer infibülasyona bağlı idrar yapma zorluğu varsa defibülasyon cerrahisi için hekime yönlendirin. ${ }^{[7]}$

\section{Üriner Sistem Enfeksiyonlarının Yönetimi}

- ÜSE'nin nedenini anamnez alarak veya genital muayene yaparak tespit etmeye çalısın. Genital muayene için kadından izin alın.

- Kadına geçen yıl içinde benzer semptomları yaşayıp yaşamadığını ve tanı konulmuş bir ÜSE olup olmadığını sorun.

- Enfeksiyon nedenini belirlemek için vulva bölgesini dikkatlice inceleyin.

- Laboratuvar olanağı varsa tedaviye başlamadan önce idrar analizi için bir idrar örneği gönderin.

- Hekim istemine göre yerel, ulusal rehberler veya laboratuvar koşullarına göre farklı protokollerde antibiyotik tedavisine başlayın.

- Kadına bol su içmesini tavsiye edin.

- Belirtiler düzelmez ve kötüleşirse veya tekrarlarsa kadına bakım için tekrar gelmesini önerin. ${ }^{[7]}$

Kadın tekrarlayan ÜSE yaşarsa ileri bir bakım merkezine sevk edin. Üretral açılıkta bir zarar görülürse ÜSE için tedavi sağladıktan sonra cerrahi revizyon için yönlendirin. Eğer ÜSE nedeni infibülasyon ise, defibülasyon konusunda kadını bilgilendirin ve danışmanlık yapın. Defibülasyon yapılmadığı sürece durumun daha kötüye gidebileceği, enfeksiyonun mesane ve böbreklere ilerleyebileceğini bildirin. Defibülasyon için bilgilendirilmiş onamını alın ve işlemi başlatmak için başvurusunu yapın. Tip III kadın sünneti olanlarda özellikle ürolojik komplikasyonların önlenmesi ve tedavisinde defibülasyon önerilmektedir ${ }^{[7]}$.

\section{Ağrılı veya Zor İdrar Yapmanın Yönetimi}

Ağrılı veya zor idrar yapma, ÜSE ve üretral açıklığın hasar görmesi veya kısmen tıkanması nedeniyle idrar akışında zorluk yaşamasıyla ortaya çıkar. Kadın sünneti olanlarda tıkanmanın nedeni genellikle skar dokusudur. Özellikle Tip III infibülasyon uygulanan kadınlarda infibüle labia idrar geçişini engeller. Bu tıkanma mesanenin boşaltılmasını zorlaştırır, idrar damla damla akar ve sonrasında sızıntı olabilir, mesanenin tamamen boşalmadığı hissi olur. ${ }^{[7]}$ Hemşirelik yaklaşımında izlenecek adımlar;

- Tıbbi öykü alarak ağrılı veya zor idrar yapma nedenini belirlemeye çalışın. Kadına nasıl idrar yaptığını sorun. Aşağıdaki sorular, hastanın kısmi bir tıkanıklığı olup olmadığını belirlemenize yardımcı olabilir;

- Mesanenizi ne kadar sürede boşaltıyorsunuz?

- Damla damla idrar yapar misiniz?

- Mesanenizin tamamen boşalmadığını hissettiğiniz oluyor mu?

- Günlük aktiviteleriniz sırasında idrar kaçırdığınız oluyor mu?

- Öykü aldıktan sonra kadının iznini alarak genital muayene yapın. Enfeksiyon nedenini belirlemek için vulva bölgesini dikkatlice inceleyin.

- Ağrının sebebi ÜSE ise gerekli prosedürleri uygulayın. ${ }^{[7]}$ Üretral açıklıkta bir hasar görürseniz kadını cerrahi revizyon için yönlendirmelisiniz. Eğer sorunun nedeni infibülasyon ise defibülasyon konusunda kadını bilgilendirin ve danışmanlık yapın. Defibülasyon için bilgilendirilmiş onamını alın ve işlemi başlatmak için başvurusunu yapın. ${ }^{[7]}$

Kadın sünnetinin kültürel yönünü düşünerek hemşirelerin kadın sünnetine yönelik incelemeleri kolaylaştırmak amacıyla Madeleine Leininger'in oluşturduğu Gün Doğuşu (Rising Sun) Transkültürel hemşirelik modeline dayanarak adaptasyon oluşturulmuştur. Bu model kapsamında olguyu araştırmak, olası risklere karşı koruyucu yaklaşımlarda bulunmak ve yeni kadın sünneti vakalarında palyatif önlemler almak mümkün olmaktadır. ${ }^{[28]}$ Bu model dört seviyede bakım yaklaşımı içerir;

Seviye I. En temel seviye olup, kadın sünnetinin kökenini ve doğasını kültürel bakım kapsamında inceler. Bu geleneğin kadın sünnetini uygulayan kültürlerin dünya görüşü bu düzeyde temsil edilir. ${ }^{[28]}$

Seviye II. Bu seviye, kadın sünnetini kadınların için koruyucu bir faktör olarak gören birey, aile ve kurumlar hakkında bilgi sağlar (kültürel bakım). ${ }^{[28]}$

Seviye III. Bu seviye, sağlık hizmetlerinde çeşitliliği teşvik etmek ve topluma bir bütün olarak sağlık hizmeti 
vermek için geleneksel ve profesyonel sistemleri ifade eder. Bu seviye disiplinler arası, sistemler arası girişimler, zararlı geleneksel uygulamalar ve kadın sünnetine karşı mücadelede hayati öneme sahiptir. ${ }^{[28]}$

Seviye IV. Bu daha spesifik bir seviye olup, kadın sünneti uygulamasının kademeli olarak terk edilmesini ve/ veya kadının ablasyonundan kaynaklanan komplikasyonların palyatif bakımını sağlamak için hemşirelik bakım planı geliştirilmesini içerir. ${ }^{[28]}$

IVa. Kültürel bakımı koruma veya sürdürme eylemleri: hem bireysel hem de toplumsal refah için yarar sağlayan uygulamalar ve değerleri içerir. ${ }^{[28]}$

IVb. Kültürel bakımı uygulama ve müzakere etme eylemleri: bireysel ve toplumsal refah açısından zararsız olan kültürel uygulama ve değerleri korumak ve uyarlamak için alınan kararları içerir. ${ }^{[28]}$

IVc Kültürel bakımın yeniden yönlendirilmesine veya yeniden yapılandırılmasına yönelik eylemler: Kadın sünneti gibi bireysel ya da toplumsal refah için zararlı yaşam tarzlarını, değerlerini ve uygulamalarını değiştirmeyi amaçlar. ${ }^{[28]}$

\section{SONUÇ}

Kadın sünneti global ölçekte önemini koruyan bir sorundur. Bu uygulamaya maruz kalan kadınları hemşireler başta olmak üzere ortaya çıkarmak tüm sağlık profesyonellerinin görevidir. Kadın sünneti, bir insanlık suçu olarak sayılmaktadır ve kadın sağlığına herhangi bir yararı bulunmamaktadır. Doğrudan genital bölgeye uygulanan travmatik işlem özellikle Tip III kadın sünnetinde ürolojik yönden hem akut hem de kronik problemlere yol açabilmektedir. Akut idrar retansiyonu, üriner sistem enfeksiyonları ve ağrılı/zor idrar yapma en önemli problemler arasındadır. Ürojinekolojik problemler konusunda çalışmalar bulunmaktadır ve üriner inkontinans problemlerinin kadın sünneti olan kadınlarda daha fazla ortaya çıktığı gösterilmiştir, ancak klinik kanıtlar çok sınırlıdır. Hemşirelik bakımında da en önemli konu, mahremiyet ve kadın hakları savunucusu rolü ile ortaya çıkmaktadır. Kadın sünneti açısından riskli bölgelerden gelen kız çocukları daha sünnet olmadan tanılanarak gerekli girişimlerde bulunulmalıdır. Aileyi bakımın merkezine alarak bütüncü yaklaşım ile uygulamanın olası yan etkileri ve zararları anlatılmalıdır. Kadın sünneti olmuş bir vaka mutlaka ürogenital problemler açısından değerlendirilmeli ve gerekli bakım girişimleri uygulanmalıdır. Transkültürel hemşirelik bakımının bir parçası olarak Leininger'in modelinden kadın sünneti olmuş bireylere uygulanabilecek bir model olarak yararlanılabilir.

\section{Hakem Değerlendirmesi}

Dış bağımsız.

Çıkar Çatışmas

Yazarlar çıkar ilişkisi olmadığını beyan etmişlerdir.

Finansal Destek

Herhangi bir mali destek alınmamıştır.

\section{Peer-review}

Externally peer-reviewed.

Conflict of Interest

No conflict of interest was declared by the authors.

Financial Disclosure

No financial disclosure was received.

\section{KAYNAKLAR}

1. WHO. Female genital mutilation, 2018. https://www.who.int/ news-room/fact-sheets/detail/female-genital-mutilation

2. UNICEF. Female Genital Mutilation/Cutting: a Global Concern. $2016.2 \quad$ https://data.unicef.org/resources/ female-genital-mutilationcutting-global-concern/

3. Zurynski Y, Sureshkumar P, Phu A, Elliott E. Female genital mutilation and cutting: A systematic literature review of health professionals' knowledge, attitudes and clinical practice. BMC Int Health Hum Rights 2015;15:1-18. [CrossRef]

4. OHCHR, UNAIDS, UNDP, UNECA, UNESCO, UNFPA, UNHCR, UNICEF, UNIFEM, WHO. Eliminating Female genital mutilation. An interagency statement. Geneva: WHO; 2008. https://www.refworld.org/ pdfid/47c6аa6e2.pdf

5. WHO. WHO guidelines on the management of health complications from female genital mutilation. 2016. http://apps.who.int/iris/ bitstream/10665/206437/1/9789241549646_eng.pdf?ua=1\%0Ahttp:// www.ncbi.nlm.nih.gov/pubmed/27359024\%0Ahttp:// ww w.who.int/reproductivehealth/topics/fg m/ management-health-complications-fgm/en/

6. Zambon JP, Mihai B, Ivan CA, Magalhaes SR, Karakci A, Zhao S. Urological complications in women with genital mutilation. Clin Med Rep 2018;1:1-4. [CrossRef]

7. WHO. Care of Girls and Women Living with Female Genital Mutilation -A clinical handbook; 2018. http://www.who.int/reproductivehealth/ publications/health-care-girls-women-living-with-FGM/en/

8. Millet $P$, Vinchant $M$, Sharifzadehgan $S$, Vieillefosse $S$, Hatem-Gantzer $G$, Deffieux X. Troubles fonctionnels du bas appareil urinaire après mutilation sexuelle féminine: revue de la littérature. Progrès Urol 2019;29:209-15. [CrossRef]

9. Geynisman-Tan J, Milewski A, Dahl C, Collins S, Mueller M, Kenton K, Lewicky-Gaupp C. Lower Urinary Tract Symptoms in Women With Female Genital Mutilation. Female Pelvic Med Reconstr Surg 2019;25:157-60. [CrossRef]

10. Berg RC, Underland V, Odgaard-Jensen J, Fretheim A, Vist GE. Effects of female genital cutting on physical health outcomes: A systematic review and meta-analysis. BMJ Open 2014;4:e006316. [CrossRef]

11. Amin $M M$, Rasheed $S$, Salem E. Lower urinary tract symptoms following female genital mutilation. Int J Gynecol Obstet 2013;123:21-3. [CrossRef]

12. Obermeyer $\mathrm{CM}$. The consequences of female circumcision for health and sexuality: An update on the evidence. Cult Heal Sex 2005;7:44361. [CrossRef]

13. lavazzo C, Sardi TA, Gkegkes ID. Female genital mutilation and infections: A systematic review of the clinical evidence. Arch Gynecol Obstet 2013;287:1137-49. [CrossRef]

14. Kaplan A, Hechavarría S, Martín M, Bonhoure I. Health consequences of female genital mutilation/cutting in the Gambia, evidence into action. Reprod Health 2011;8:26. [CrossRef]

15. Elnashar A, Abdelhady R. The impact of female genital cutting on health of newly married women. Int J Gynecol Obstet 2007;97:238-44. [CrossRef] 
16. Abdulcadir J, Dällenbach P. Overactive bladder after female genital mutilation/cutting (FGM/C) type III. BMJ Case Rep 2013:bcr2012008155. [CrossRef]

17. Birge O, Erkan MM, Serin AN. Case report: epidermoid inclusion cyst of the clitoris as a long-term complication of female genital mutilation. J Med Case Rep 2019;13:109. [CrossRef]

18. Rouzi AA, Sahly N, Alhachim E, Abduljabbar H. Type I Female Genital Mutilation: A Cause of Completely Closed Vagina. J Sex Med 2014;11:2351-3. [CrossRef]

19. Sow A, Diagne G, Keita Y, Sow O, Ndiath A, Ouattara A, et al. Mutilation génitale féminine fatale chez une fille de 10 ans. Arch Pédiatrie 2017;24:991-4. [CrossRef]

20. Jaleel $H$, Huengsberg $M$, Luesley D. Female genital mutilation -case report and discussion. Int J STD AIDS 2002;13:850-1. [CrossRef]

21. Craven S, Kavanagh A, Khavari R. Female genital mutilation management in the ambulatory clinic setting: a case study and review of the literature. J Surg Case Rep 2016;2016:rjw104. [CrossRef]

22. Arslan D, Bozkurt O, Birge Ö, Demir Ö, Esen A, TürkH, et al. A Complication of Female Circumcision: Vaginal Stenosis and Total Incontinence Due to Urethral Intercourse. J Urol Surg 2015;2:91-3. [CrossRef]
23. Okwudili $\mathrm{O}$, Chukwudi $\mathrm{O}$. Urinary and genital tract obstruction as a complication of female genital mutilation: case report and literature review. J Surg Tech Case Rep 2012;4:64. [CrossRef]

24. Momoh $C$, Olufade $O$, Redman-Pinard $P$. What nurses need to know about female genital mutilation. Br J Nurs 2016;25:S30-4. [CrossRef]

25. EduCare. Multi-agency statutory guidance on female genital mutilation, 2016. https://www.educare.co.uk/news/ multi-agency-statutory-guidance-on-female-genital-mutilation

26. Royal College of Nursing. Female Genital Mutilation -An RCN Resource for Nursing and Midwifery Practice: Acknowledgements, 2nd ed. London; 2016.

27. Rose B. Female genital mutilation in the UK: Considerations for best nursing practice. Br J Nurs 2019;28:788-91. [CrossRef]

28. Jiménez-Ruiz I, Martínez AP. Female genital mutilation and transcultural nursing: adaptation of the Rising Sun Model. Contemp Nurs 2017;53:196-202. [CrossRef] 